OPEN ACCESS

Edited by:

Angel Lanas,

University of Zaragoza, Spain

Reviewed by:

Mohammad Bashashati, Texas Tech University Health Sciences

Center, United States

Nazri Mustaffa,

Universiti Sains Malaysia

(USM), Malaysia

*Correspondence:

Min-Hu Chen

chenminhu@mail.sysu.edu.cn

Ren Mao

maor5@mail.sysu.edu.cn

Marietta lacucc

m.iacucci@bham.ac.uk

tThese authors have contributed equally to this work

Specialty section

This article was submitted to

Gastroenterology,

a section of the journal

Frontiers in Medicine

Received: 02 October 2020 Accepted: 11 December 2020 Published: 12 January 2021

Citation:

Li X-Z, Qiu Y, Jeffery L, Liu F, Feng R He J-S, Tan J-Y, Ye Z-Y, Lin S-N, Ghosh S, lacucci M, Chen M-H and Mao R (2021) Down-Regulation of

Colonic ACE2 Expression in Patients With Inflammatory Bowel Disease Responding to Anti-TNF Therapy: Implications for COVID-19.

Front. Med. 7:613475. doi: 10.3389/fmed.2020.613475

\section{Down-Regulation of Colonic ACE2 Expression in Patients With Inflammatory Bowel Disease Responding to Anti-TNF Therapy: Implications for COVID-19}

\author{
Xiao-Zhi Li ${ }^{1+}$, Yun Qiu ${ }^{1 \dagger}$, Louisa Jeffery ${ }^{2,3+}$, Fen Liu ${ }^{1}$, Rui Feng ${ }^{1}$, Jin-Shen He ${ }^{1}$, Jin-Yu Tan ${ }^{1}$, \\ Zi-Yin Ye ${ }^{4}$, Si-Nan Lin ${ }^{1}$, Subrata Ghosh ${ }^{2,3}$, Marietta lacucci ${ }^{2,3 *}$, Min-Hu Chen ${ }^{1 *}$ and \\ Ren $\mathrm{Mao}^{1 *}$ \\ ${ }^{1}$ Department of Gastroenterology, The First Affiliated Hospital of Sun Yat-sen University, Guangzhou, China, ${ }^{2}$ Institute of \\ Immunology and Immunotherapy, University of Birmingham, Birmingham, United Kingdom, ${ }^{3}$ National Institute for Health \\ Research Biomedical Research Center, University of Birmingham and University Hospitals Birmingham NHS Foundation \\ Trust, Birmingham, United Kingdom, ${ }^{4}$ Department of Pathology, The First Affiliated Hospital of Sun Yat-sen University, \\ Guangzhou, China
}

Background and Aims: Angiotensin-converting enzyme II (ACE2) is the key molecule for understanding the pathophysiology of COVID-19. The risk of COVID-19 and impact of immunosuppressive treatment on disease course in patients with inflammatory bowel disease (IBD) remain controversial. We aimed to determine the change of intestinal ACE2 expression before and after biologics treatment including anti-tumor necrosis factor $\alpha$ (anti-TNF $\alpha$ ), anti-integrin, and anti-interleukin (IL)12/23 in IBD patients.

Methods: We analyzed the ACE2 expression through the public database of paired intestinal biopsies from IBD patients before and after biologic therapy. Change of ACE2 RNA and protein expression were validated in two independent cohorts (Birmingham cohort and Guangzhou cohort). The correlation between ACE2 expression and disease activity was also analyzed.

Results: Mining information from the GEO database showed that compared with healthy control, intestinal ACE2 expression was downregulated in ileum of CD patients, while upregulated in colon of both CD and UC patients. Colonic ACE2 RNA expression was decreased significantly in patients responding to anti-TNF $\alpha$ but not anti-integrin and anti-IL12/23, which was validated in the Birmingham cohort. Using the Guangzhou cohort including 53 patients matched by pre- and post-anti-TNF $\alpha$ therapy, colonic ACE2 protein expression was significantly downregulated after anti-TNF $\alpha$ treatment in responders $(P<0.001)$ rather than non-responders. Colonic ACE2 expression was significantly higher in patients with severe histologically active disease compared with those with moderate $(P<0.0001)$ and mild $(P=0.0002)$ histologically active disease.

Conclusion: Intestinal inflammation influences the expression of intestinal ACE2 in IBD patients, with different alterations in the ileum and colon. Colonic ACE2 expression was 
downregulated after anti-TNF $\alpha$ therapy in IBD patients responding to treatment. This might provide new clues regarding the risk of SARS-CoV-2 infection and the potential benefit of sustaining anti-TNF $\alpha$ treatment in patients with IBD.

Keywords: COVID-19, ACE2, inflammatory bowel disease, intestine, anti-TNF $\alpha$

\section{INTRODUCTION}

The outbreak of coronavirus disease 2019 (COVID-19), caused by severe acute respiratory syndrome coronavirus 2 (SARS$\mathrm{CoV}-2)$, has widely spread around the world. Angiotensinconverting enzyme II (ACE2) has emerged as a key molecule in the pathophysiology of COVID-19 (1). ACE2 is expressed in the respiratory tract as well as gastrointestinal tract $(2,3)$. Emerging data (4-7) showed that the SARS-CoV-2 may actively infect and replicate in the human gut enterocytes or organoids and might be transmitted via fecal-oral transmission.

Given the use of immunosuppressive agents as well as malnutrition status, patients with inflammatory bowel disease (IBD) are generally at increased risk of infection. Unexpectedly, current epidemiology of SARS-CoV-2 infection in IBD patients, including published reports from China (8), Spain (9), Italy (10, 11), and the global data from the SECURE-IBD registry (https:// covidibd.org/) (12), did not support a higher risk of COVID-19 in IBD patients compared to that in the general population.

Similar immune signatures in IBD and COVID-19 indicate that medications of IBD may play a potential role in the treatment of COVID-19. Some studies supported that infliximab downregulated ACE2 expression in colon tissue of $\operatorname{IBD}(13,14)$. Another recent study has showed that biologics and steroids are linked to the significantly lower expression of ACE2 in intestinal lamina propria CD11b-enriched cells (15). However, to our knowledge, few studies have investigated the influence of biologics on ACE2 expression in gut enterocytes which are directly exposed to the virus. Our study identified the ACE2 expression with the public database and then validated RNA and protein expression using clinical samples from two independent cohorts including China and the UK aiming to determine the alter expression of intestinal ACE2 especially in enterocytes before and after biologic therapy including anti-tumor necrosis factor $\alpha$ (anti-TNF $\alpha$ ), anti-integrin and anti-interleukin (IL) $12 / 23$ in IBD patients.

\section{METHODS}

\section{Transcriptomic Change of Intestinal ACE2 Pre- and Post-biologic Therapy From the Gene Expression Omnibus (GEO) Database}

We searched the gene expression data sets regarding biologics in IBD in the GEO database (http://www.ncbi.nlm.nih.gov/ geo/) with the key words "Inflammatory bowel disease/Crohn's disease/Ulcerative colitis/IBD/CD/UC", "intestine/tissue" and "Homo sapiens." The inclusion criteria from the data sets were: (1) intestinal tissue from patients with IBD; (2) paired samples were collected before and after various biologics and small molecule inhibitors therapy including but not limited to anti$\mathrm{TNF} \alpha$, anti-integrin, and anti-IL12/23; (3) therapeutic efficacy (i.e., response or not) of each patient was described; (4) the number of samples per group was not $<12(16)$. We extracted the expression value of ACE2 and used two-class paired or unpaired analyses according to experimental design. Value distributions were evaluated.

\section{Validation of Intestinal ACE2 RNA Expression Change by Real-Time Quantitative Polymerase Chain Reaction (RT-qPCR) Pre- and Post-anti-TNF $\alpha$ \\ Therapy}

This validation was conducted in a cohort at the University of Birmingham, UK. Colonoscopy-confirmed active UC and $\mathrm{CD}$ patients were recruited prior to initiation of anti-TNF $\alpha$ (Infliximab [IFX] or adalimumab [ADA]) therapy. Institutional research ethics approval was obtained for the study and all patients had signed informed consent.

Colonoscopic biopsies were taken from the inflamed segments of IBD patients (UC and CD) before and 12-16 weeks after starting treatment with biologics. The endoscopic response was judged by Mayo endoscopic score $0-1$ or Simple Endoscopic Score-CD decrease of $50 \%$ or greater at week 12-16 compared to baseline (17). Biopsies were transferred immediately to "RNA later" upon collection and stored at $4^{\circ} \mathrm{C}$ prior to lysis and gentleMACS homogenization (Miltenyi Biotec) followed by RNeasy on-column RNA extraction and purification (Qiagen). RNA was quantified by Qubit (Life Technologies) and $1.5 \mu \mathrm{g}$ reverse transcribed using iScript reagents (BioRad). Expression of ACE2 receptor relative to 18SrRNA was measured by qPCR using Taqman reverse transcription gene-assays (18SrRNA: 4319413E. ACE2: Hs01085333_m1) (Life Technologies). Reactions were performed in triplicate as singleplex assays and expression of ACE2 relative to 18SrRNA calculated by $10^{6}\left(2^{-\mathrm{dCt}}\right)$. The expression change between preand post-treatment was tested.

\section{Validation of Intestinal ACE2 Protein Expression Change Using Immunohistochemistry (IHC) Assays Pre- and Post-anti-TNF $\alpha$ Treatment}

To determine the protein expression of ACE2 in the intestinal epithelial cells, patients with $\mathrm{CD}$ receiving anti-TNF $\alpha$ treatment were included from the First Affiliated Hospital of Sun Yatsen University, Guangzhou, China. All patients underwent colonoscopy by gastroenterologists with more than 5 years of experience in IBD before and 12-14 weeks after anti-TNF $\alpha$ 
treatment, and all biopsies were taken from inflamed gut segments. Institutional research ethics approval was obtained for the study.

IHC was performed using paraffin-embedded tissues from intestinal mucosal biopsies obtained during endoscopy from the IBD patients mentioned above. Tissue sections were deparaffinized in xylene and hydrated through a graded series of alcohol to tap water. Antigen was retrieved in citrate buffer for $20 \mathrm{~min}$ and cooled to room temperature. The sections were incubated with $3 \% \mathrm{H}_{2} \mathrm{O}_{2}$ in distilled water for $15 \mathrm{~min}$. After being rinsed three times with phosphate-buffered saline (PBS), the sections were incubated with rabbit polyclonal IgG primary antibodies against ACE2 (1:500 dilution, ab15348; Abcam; USA) overnight at $4^{\circ} \mathrm{C}$. Then, the sections were incubated with the secondary antibody (1:50000, ab205718; Abcam; USA) for $30 \mathrm{~min}$ at room temperature, followed by two times $5 \mathrm{~min}$ washing with PBS. Finally, the sections were stained with hematoxylin. The protein expression of ACE2 was evaluated in a random and blinded fashion and was assigned an IHC score, which was based on the approximate percentage of positively stained cells over overall intestinal epithelial cells (ranging from 0 to 100\%), as described in previously published methods (18).

\section{Assessment of Disease Activity and Definition of Outcome}

The disease activity of the CD patients from the China cohort was analyzed using endoscopic and histologic assessment. The Crohn's Disease Endoscopic Index of Severity (CDEIS) score was used for endoscopic scoring. Consistent with the STRIDE guidelines (17), a decrease by $>5$ or at least $50 \%$ from baseline in CDEIS demonstrates endoscopic response. A semiquantitative evaluation for endoscopic disease activity was given as follows: CDEIS $<3$ suggested inactive, 3-8 mildly active, 9-12 moderately active, and $>12$ severely active (19).

Histological disease activity was assessed by a blinded IBD experienced pathologist in random order. The modified Global Histologic Disease Activity Score (mGHAS) $(20,21)$ was used and the histologic response was defined as modified GHAS $\leq 4$ in those patients with baseline score $>4$. A semiquantitative evaluation for histological disease activity was given as follows: inactive, 0 ; mildly active, 1-5; moderately active, $6-10$; and severely active, 11-14.

\section{Statistical Analysis}

The original expression data was collected and then plotted by GraphPad Prism 8 (GraphPad Software, La Jolla, CA). All statistical analyses were performed IBM SPSS Statistics 25.0 software package (IBM, Armonk, NY, USA). Continuous variables were summarized as medians and interquartile ranges (IQRs). The Student's $t$-test or analysis of variance (ANOVA) test was used for parametric tests, while the Wilcoxon signed-rank test or Kruskal-Wallis test was performed for non-parametric tests. The Spearman correlation was used to evaluate the relationship of IHC score and endoscopic or histological disease activity score. All statistical testing was two-sided, and $P<$ 0.05 was considered significant and indicated as follows: ns, not significant; ${ }^{*} P \leq 0.05 ;{ }^{* *} P \leq 0.01 ;{ }^{* * *} P \leq 0.001 ;{ }^{* * * *} P \leq 0.0001$.

\section{RESULTS}

\section{Intestinal ACE2 Expression in GEO Database}

Five GEO datasets [GSE16879 (22), GSE23597 (23), GSE92415 (24), GSE73661 (25), and GSE112366 (26)] were included in the final analysis. Detailed information for datasets included was summarized in Table 1. Compared with healthy control, intestinal ACE2 expression was downregulated in ileum of CD patients (GSE16879), while upregulated in colon of both CD and UC patients (GSE16879, GSE92415, and GSE73661), significantly.

As shown in Figures 1A-C, ACE2 expression in colon tissue was decreased significantly in patients responding to antiTNF $\alpha$ (except GSE23597). On the contrary, ACE2 in ileum tissue was upregulated significantly in CD patients using anti$\mathrm{TNF} \alpha$ regardless of the response status (GSE16879). Intestinal ACE2 expression did not decrease after VDZ or UST treatment (Figures 1D,E).

\section{Colonic ACE2 RNA Expression Was Downregulated in IBD Patients Responding to anti-TNF $\alpha$}

In the UK cohort, we studied 24 IBD patients (11CD, 13 UC) initiating biologic therapies (CD 8 ADA, 2 IFX, 1 UST; UC 5 ADA, 4 IFX, 4 VDZ). The baseline characteristics of patients are shown in Table 2. Figure 1 F shows a statistically significant decrease in colonic expression of ACE2 in responders $(n=11)$ to anti-TNF $\alpha(P=0.0250)$. Non-responders to anti$\mathrm{TNF} \alpha(4 \mathrm{UC}, 1 \mathrm{CD})$ did not exhibit any significant decrease in ACE2 expression. Patients treated with VDZ did not show any significant decrease in ACE2 expression.

\section{Colonic ACE2 Protein Expression Was Downregulated in CD Patients Responding to anti-TNF $\alpha$}

In the China cohort, we included $66 \mathrm{CD}$ patients for IHC validation and found 53 patients matched by pre- and post-anti-TNF $\alpha$ therapy (Supplementary Table 1). The baseline characteristics of patients are shown in Table 2. As demonstrated in Figure 2A, in both endoscopic and histologic assessments, ACE2 expression was significantly downregulated in colonic biopsy after anti-TNF $\alpha$ treatment in responders $(P<0.001)$ rather than non-responders (the representative IHC images are shown in Figure 2D). Besides, ACE2 protein expression in ileum increased after anti-TNF $\alpha$ treatment in responders $(n=3)$. There was no difference in ACE2 protein expression in colon or ileum of non-responders.

\section{Colonic ACE2 Protein Expression Positively Correlated With Disease Activity}

We studied 147 specimens with different disease activity from total CD patients of the China cohort. Colonic ACE2 expression was significantly higher in patients with severe histologically active disease compared with those with moderate $(P<0.0001)$ and mild $(P=0.0002)$ histologically active disease. Ileal ACE2 
TABLE 1 | Summary of included GEO datasets.

\begin{tabular}{|c|c|c|c|c|c|c|c|c|c|c|c|c|c|}
\hline \multirow[t]{3}{*}{ Patients Cohort } & \multirow{3}{*}{$\begin{array}{l}\text { Healthy } \\
\text { Control }\end{array}$} & \multicolumn{4}{|c|}{ IBD Type } & \multicolumn{2}{|c|}{ Response or not } & \multirow{3}{*}{$\begin{array}{l}\text { Matched } \\
\text { Comparison } \\
\text { (Yes/No) }\end{array}$} & \multirow{3}{*}{$\begin{array}{l}\text { Sample } \\
\text { Source }\end{array}$} & \multirow{3}{*}{$\begin{array}{l}\text { Study Time } \\
\text { Point }^{\mathrm{C}}\end{array}$} & \multirow{3}{*}{$\begin{array}{l}\text { Definition of } \\
\text { Outcome }^{d}\end{array}$} & \multirow[t]{3}{*}{ Treatment } & \multirow{3}{*}{$\begin{array}{l}\text { GEO } \\
\text { Dataset }\end{array}$} \\
\hline & & \multicolumn{3}{|c|}{$\mathbf{C D}^{\mathrm{a}}$} & \multirow[t]{2}{*}{ UC } & \multirow{2}{*}{$\begin{array}{l}\text { Responders } \\
\text { Pair }^{\mathrm{b}}\end{array}$} & \multirow{2}{*}{$\begin{array}{l}\text { Non-responders } \\
\text { Pair }\end{array}$} & & & & & & \\
\hline & & $\begin{array}{l}\text { Ileal } \\
\text { CD } \\
\text { (L1) }\end{array}$ & $\begin{array}{l}\text { Colonic } \\
\text { CD (L2) }\end{array}$ & $\begin{array}{l}\text { Ileocolonic } \\
\text { CD (L3) }\end{array}$ & & & & & & & & & \\
\hline $\begin{array}{l}\text { Leuven, Belgium } \\
\text { (20) }\end{array}$ & 12 & 18 & 19 & 0 & 24 & $\begin{array}{l}28 \\
\text { L1: } 8 \\
\text { L2: } 12 \\
\text { UC: } 8\end{array}$ & $\begin{array}{l}33 \\
\text { L1: } 10 \\
\text { L2: } 7 \\
\text { UC: } 16\end{array}$ & Yes & $\begin{array}{l}\text { ileum (L1), } \\
\text { colon (L2) }\end{array}$ & weeks $0,4 / 6$ & $\begin{array}{l}\text { Endoscopic } \\
\text { and } \\
\text { Histological } \\
\text { score }\end{array}$ & $\begin{array}{l}\text { IFX } \\
(5 \mathrm{mg} / \mathrm{kg})\end{array}$ & GSE16879 \\
\hline ACT1 study (21) & 0 & 0 & 0 & 0 & 48 & $\begin{array}{l}49 \\
\text { IFX/PBO } \\
\text { w0-8: 18/3 } \\
\text { IFX/PBO } \\
\text { w0-30: 14/4 } \\
\text { IFX/PBO } \\
\text { w0-8-30: 9/1 }\end{array}$ & $\begin{array}{l}28 \\
\text { IFX/PBO } \\
\text { w0-8: } 7 / 5 \\
\text { IFX/PBO } \\
\text { w0-30: 5/6 } \\
\text { IFX/PBO } \\
\text { w0-8-30: 3/2 }\end{array}$ & Yes & colon & $\begin{array}{l}\text { weeks 0, 8, } \\
30\end{array}$ & $\begin{array}{l}\text { Endoscopic } \\
\text { score }\end{array}$ & $\begin{array}{l}\mathrm{IFX}(5 / 10 \\
\mathrm{mg} / \mathrm{kg}) \\
\mathrm{PBO}\end{array}$ & GSE23597 \\
\hline $\begin{array}{l}\text { PURSUIT-SC } \\
\text { study (22) }\end{array}$ & 21 & 0 & 0 & 0 & 162 & $\begin{array}{l}82 \text { (unpaired) } \\
\text { GLM w0/6: } \\
32 / 29 \\
\text { PBO w0/6: } \\
11 / 10\end{array}$ & $\begin{array}{l}80 \text { (unpaired) } \\
\text { GLM wO/6: 27/21 } \\
\text { PBO wO/6: 17/15 }\end{array}$ & No & colon & weeks 0,6 & $\begin{array}{l}\text { Endoscopic } \\
\text { score }\end{array}$ & GLM & GSE92415 \\
\hline GEMINI study (23) & 12 & 0 & 0 & 0 & 67 & $\begin{array}{l}29 \\
\text { IFX w0-4/6: } 8 \\
\text { VDZ w0-6: } 6 \\
\text { VDZ w0-12: } 5 \\
\text { VDZ w0-52: } \\
10\end{array}$ & $\begin{array}{l}51 \\
\text { IFX w0-4/6: } 15 \\
\text { VDZ w0-6: } 21 \\
\text { VDZ w0-12: } 10 \\
\text { VDZ w0-52: } 5\end{array}$ & Yes & colon & $\begin{array}{l}\text { IFX weeks } 0 \text {, } \\
4 / 6 \\
\text { VDZ weeks } 0 \text {, } \\
6,12,52\end{array}$ & $\begin{array}{l}\text { Endoscopic } \\
\text { score }\end{array}$ & $\begin{array}{l}\text { IFX, VDZ, } \\
\text { PBO }\end{array}$ & GSE73661 \\
\hline UNITI study (24) & 26 & 26 & 18 & 54 & 0 & $\begin{array}{l}56 \\
\text { w0-8: } 35 \\
\text { w0-44: } 21\end{array}$ & $\begin{array}{l}42 \\
\text { w0-8: } 29 \\
\text { w0-44: } 13\end{array}$ & Yes & ileum & $\begin{array}{l}\text { weeks } 0,8 \text {, } \\
44\end{array}$ & CDAl score & UST & GSE112366 \\
\hline
\end{tabular}

${ }^{a}$ Disease subtypes are classified according to Montreal classification; ${ }^{b}$ Responders/non-responders pair, one pair means that the patient has biopsy samples before and after treatment; ${ }^{\circ}$ Study time point, time to definite response status; ${ }^{d}$ Definition of outcome, Method to definite response/non-response after treatment.

IBD, inflammatory bowel disease; CD, Crohn's disease; UC, ulcerative colitis; IFX, infliximab; GLM, golimumab; VDZ, vedolizumab; UST, ustekinumab; PBO, placebo; CDAl, Crohn's Disease Activity Index. 
A

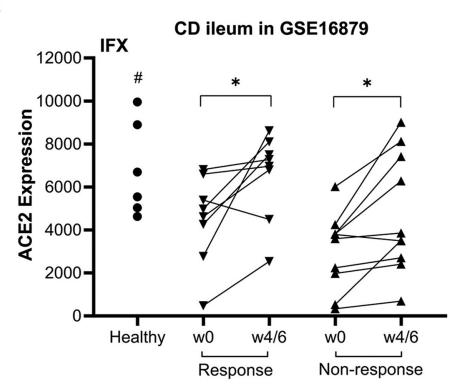

C

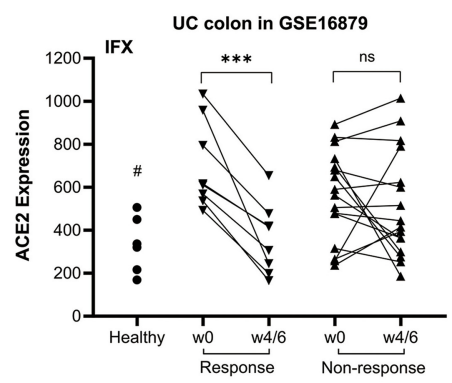

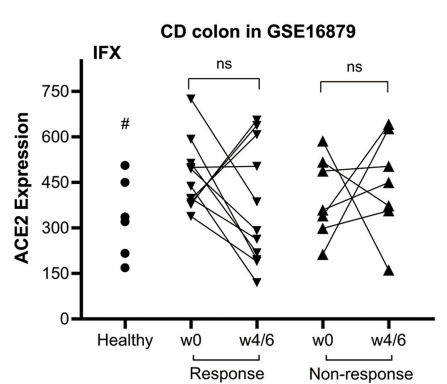

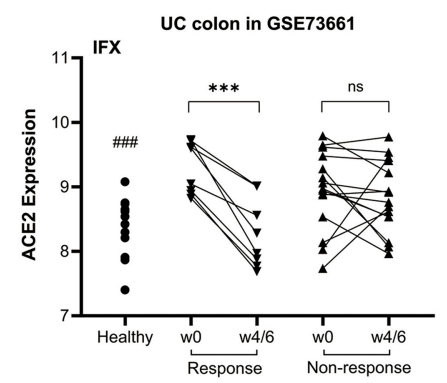

B

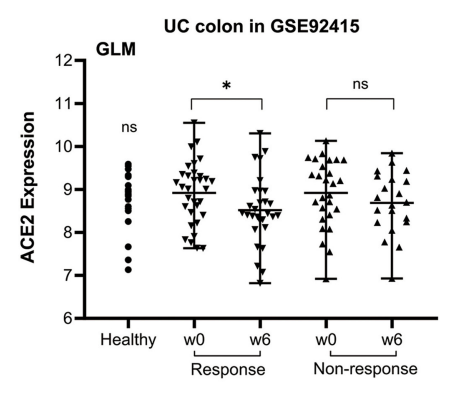

D

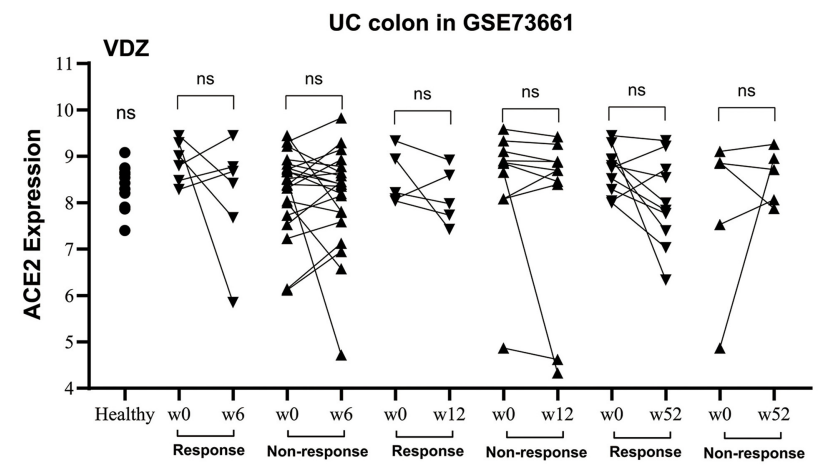

E

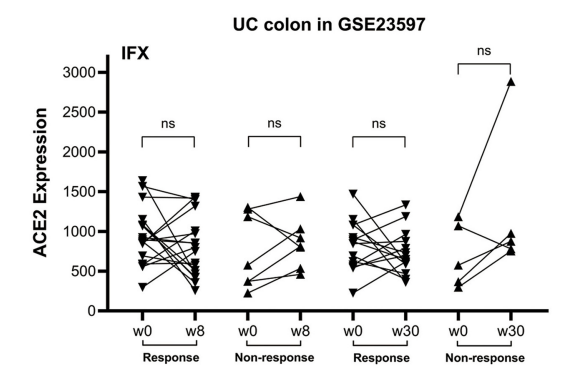

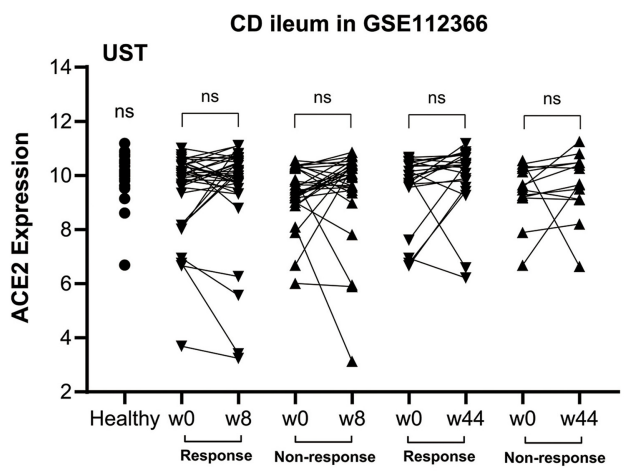

$\mathbf{F}$

\section{IBD colon with RT-qPCR}

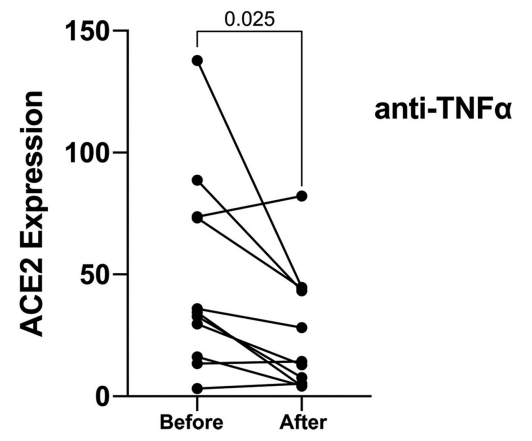

FIGURE 1 | The relative ACE2 mRNA expression level of intestinal mucosal biopsy specimens before and after biologic therapy with anti-TNF $\alpha$ (infliximab/IFX, A,C; golimumab/GLM, B), vedolizumab/NDZ (D) or ustekinumab/UST (E) in patients with CD (A,E) or UC (B-D) from GEO data sets. (F) RT-qPCR data of the intestinal mucosal ACE2 expression in IBD responders before and after anti-TNF $\alpha$ therapy. In the matched comparison (A,C-F), lines between two samples represent the change in ACE2 expression before and after treatment for one patient. In the unpaired comparison (B), mean and range are shown in the scatterplot. There was not statistical difference between the IBD patients before and after therapy. ns, not significant; ${ }^{\star} P<0.05$; ${ }^{\star \star \star} P<0.001$ (in patients after vs. before therapy). $\# P<0.05$; $\# \# \# P<0.001$ (in healthy controls vs. patients before therapy). 
TABLE 2 | Baseline characteristics of patients with inflammatory bowel disease enrolled in validation cohorts.

\begin{tabular}{|c|c|c|}
\hline Characteristics & $\begin{array}{l}\text { Total Patients } \\
\text { (China cohort) }\end{array}$ & $\begin{array}{c}\text { Total Patients } \\
\text { (UK cohort) }\end{array}$ \\
\hline No. of patients & 66 & 24 \\
\hline Male, $N(\%)$ & $43(65.2 \%)$ & $12(50 \%)$ \\
\hline \multicolumn{3}{|l|}{ Age at time of collection (years) } \\
\hline Mean (SD) & $23.4(8.9)$ & $42.0(12.6)$ \\
\hline Range & $10-46$ & $24-63$ \\
\hline \multicolumn{3}{|l|}{ Duration of disease (months) } \\
\hline Mean & $44.7(55.8)$ & $121.0(106.0)$ \\
\hline Range & $1-366$ & $6-372$ \\
\hline Crohn's Disease (CD), N & 66 & 11 \\
\hline \multicolumn{3}{|l|}{ Location, N } \\
\hline L1, lleal & 5 & 4 \\
\hline L2, Colonic & 3 & 5 \\
\hline L3, lleocolonic & 58 & 2 \\
\hline \multicolumn{3}{|l|}{ Disease behavior, $N$} \\
\hline B1, Non-stricturing, non-penetrating & 39 & 6 \\
\hline B2, Stricturing & 19 & 3 \\
\hline B3, Penetrating & 8 & 2 \\
\hline Ulcerative Colitis (UC), N & 0 & 13 \\
\hline Proctitis (E1) & 0 & 1 \\
\hline Left sided (E2) & 0 & 5 \\
\hline Extensive (E3) & 0 & 7 \\
\hline \multicolumn{3}{|l|}{ Biologics commenced, $N$} \\
\hline Anti-TNF & 66 (all CD) & 19 (10 CD, $9 \cup C)$ \\
\hline Vedolizumab & 0 & 4 (all UC) \\
\hline Ustekinumab & 0 & 1 (CD) \\
\hline
\end{tabular}

expression was comparable among different disease activity groups. When stratifying the disease activity by endoscopic score, no significant difference existed among disease activity groups (Figure 2B).

As is shown in Figure 2C, ACE2 expression positively but weakly correlated with histological disease activity $(\rho=0.3357$, $95 \%$ confidence interval $[\mathrm{CI}] 0.1502$ to $0.4983, P=0.0004)$ and endoscopic disease activity $(\rho=0.1881,95 \%$ CI $-0.0105-0.3723$, $P=0.0559)$ in colon, while no correlation existed between ileal ACE2 expression and histological or endoscopic disease activity.

\section{DISCUSSION}

There are controversies about the risk of SARS-CoV-2 infection in patients with IBD (27). It was reported that the soluble form of ACE2, which acts as a competitive binding partner for SARS$\mathrm{CoV}-2$, is up-regulated in the peripheral blood of IBD patients and then limits SARS-CoV-2 infection $(28,29)$. Several studies showed that IBD medications especially biologics could regulate the intestinal ACE2 expression of IBD (13-15). However, few studies have directly investigated the influence of biologics on ACE2 expression in gut enterocytes which are directly exposed to the virus. The two recent landmark studies $(6,7)$ have confirmed that SARS-CoV-2 could productively infect human gut enterocytes and intestinal organoids. In our study, we found that IBD patients had a higher expression of ACE2 in colon tissue while lower in ileum tissue vs. healthy control, which was consistent with the published data (13). Additionally, our result showed that the expression of colonic epithelial ACE2 was downregulated in IBD patients responding to anti-TNF $\alpha$ therapy, using GEO data analysis and then validated with qPCR and IHC assays. These results might provide new evidence and knowledge to the risk of SARS-CoV-2 infection in patients with IBD using different medications and the potential role of anti-TNF $\alpha$ in the treatment of COVID 19.

Our study demonstrated that intestinal epithelial ACE2 expression increased with more severe disease activity, which may be due to the higher inflammatory cytokines. Previous studies $(30,31)$ showed that ACE2 is increased in human bronchial epithelial cells infected by SARS-CoV-2 as a response to inflammatory cytokine stimulation including interferon (IFN)$\gamma$. Several inflammatory cytokines like IFN- $\gamma, \mathrm{TNF} \alpha$, IL-1, and IL-6 could be upregulated in active IBD patients (28). In addition, ACE2 expression was downregulated after anti$\mathrm{TNF} \alpha$ therapy only in responders rather than non-responders. In the registered IBD patients with COVID-19 from SECUREIBD (12), there were 762 patients with anti-TNF $\alpha$ therapy alone, 651 (85\%) of whom recovered without hospital admission and four patients died in total. On the contrary, $65 \%$ of 773 patients with treatment of sulfasalazine/mesalamine recovered without hospital admission and 37 patients died. These data indicated that IBD patients with anti-TNF $\alpha$ treatment might have a better outcome of COVID than other medications (32). The potential explanations may have three points: (1) antiTNF $\alpha$ treatment downregulated IFN- $\gamma$ which would induced the expression of ACE2 through downregulating IFN- $\gamma$ (32); (2) anti-TNF $\alpha$ treatment also downregulated other proinflammatory cytokines in "TNF dependent cytokine cascade," such as IL-1, IL6 and IFN- $\gamma$ which also play important roles in cytokine storm syndrome in COVID-19 (32); (3) anti-TNF $\alpha$ could induce a reduction in leucocyte trafficking due to reduction of adhesion molecules, vascular endothelial growth factor and chemokines in both IBD and COVID-19 $(33,34)$. Indeed, an urgent demand for clinical trials of anti-TNF $\alpha$ therapy for COVID-19 has been proposed recently (35). Moreover, the clinical trial of antiTNF $\alpha$ in treating COVID-19 (ChiCTR2000030089) is ongoing. Future studies investigating the protective role of anti-TNF $\alpha$ for IBD or COVID 19 patients during the COVID-19 pandemic are warranted.

Except for the regulation of inflammatory cytokines, ACE2 may participate in intestinal stem cell proliferation, mucosal healing and crypt pathology in the pathogenesis of IBD. ACE2 plays an important role in the endothelial repair in acute lung injury (36) and the healing of gastric ulcers (37), potentially through reducing Angiotensin (Ang) II and increasing the production of Ang 1-7. A recent study (38) proposed that ACE2 contributed to the proliferation of intestinal stem cells and the maintenance of epithelial barrier function in DSS-induced colitis mice. ACE2-deficient mice developed increased intestinal epithelial injury associated with crypt damage compared to the 
A

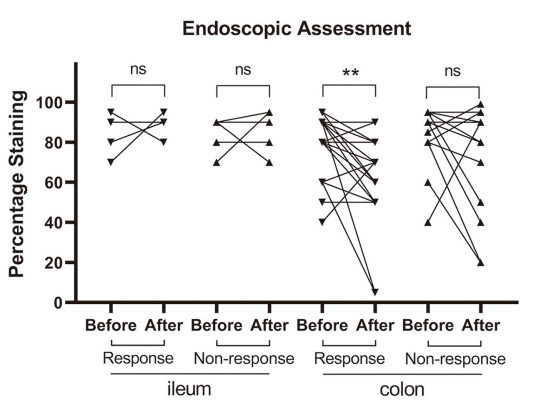

B

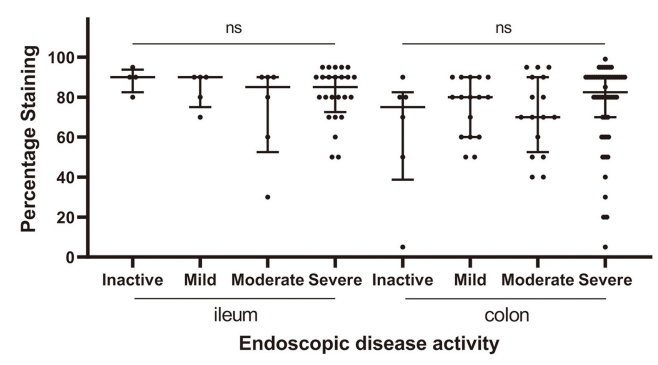

C

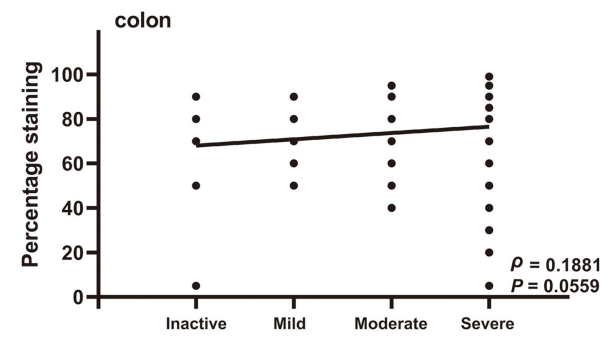

Endoscopic disease activity
Histologic Assessment
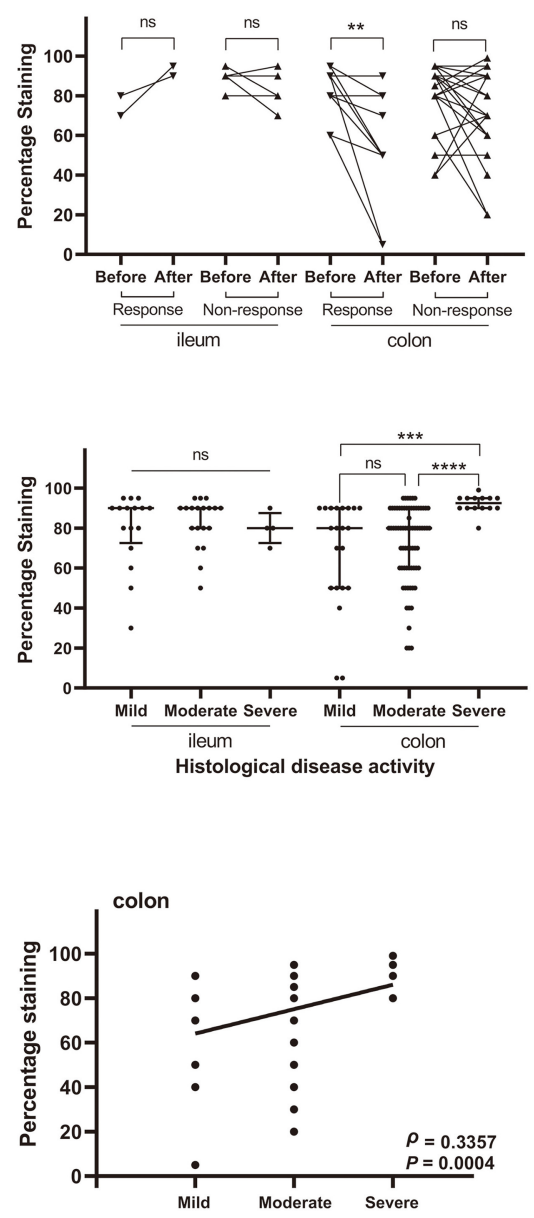

Histologic disease activity

D

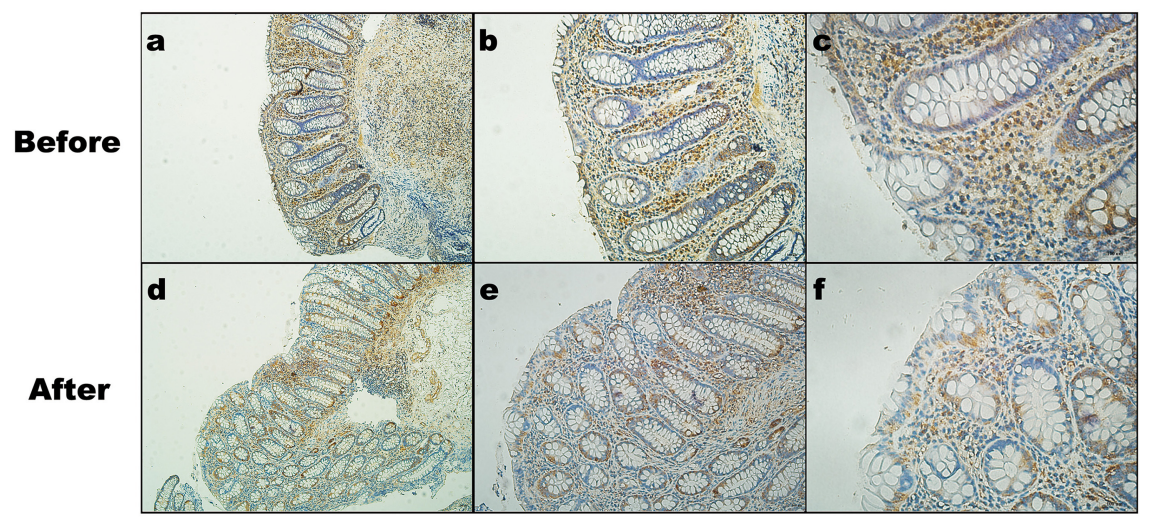

FIGURE 2 | The relative ACE2 protein expression in intestinal mucosal biopsy specimens from patients with CD by Immunohistochemistry assays. The expression level was measured by percentage of positively stained cells. The sample sizes of each group are shown in Supplementary Table 1. (A) ACE2 expression before and after anti-TNF $\alpha$ treatment (matched comparison). (B) ACE2 expression among different disease activity groups defined by endoscopic and histological assessment. Median and interquartile range are shown in the scatterplot. (C) Spearman rank correlation analysis between ACE2 expression of colonic epithelial cells and endoscopic or histological disease activity. (D) Representative images (immunohistochemical staining for ACE2) of the colonic biopsy specimens before and after anti-TNF $\alpha$ treatment. (a-c) Biopsy before treatment. The histological score is 6 . The percentage staining of ACE2 in colonic epithelial cells is $80 \%$. (d-f) Biopsy after treatment. The histological score is 1. The percentage staining of ACE2 in colonic epithelial cells is $20 \%$. All scale bars are $100 \mu \mathrm{m}$. ns, not significant; ${ }^{* \star} P<0.01 ;{ }^{* \star \star} P$ $<0.001,{ }^{\star \star \star \star} P<0.0001$ 
wild-type mice (39). However, there have been debates on the role of ACE2 in IBD. It is also reported that an ACE2 inhibitor may have an anti-inflammatory effect in DSS-induced colitis mice (40). Considering the dual role of ACE2 in the development of colitis, it warrants further study.

In the current study, a significant difference of ACE2 expression was found in responders rather than non-responders to anti-TNF $\alpha$ in IBD patients with colonic involvement, which was validated with IHC assays of CD patients in China cohort (Figure 2A). There are two patients with significant changes of ACE2, whose endoscopic and histological scores posttreatment are both close to zero. It demonstrated that the ACE2 may play an important role in the anti-TNF $\alpha$ mediated antiinflammatory pathways in colonic CD. The difference was still statistically significant when taking out these two patients. Anti$\mathrm{TNF} \alpha$ is the mainstay of CD treatment. Nonetheless, around one-third of CD patients experience a loss of response (41). Besides, ACE2 or renin-angiotensin system (RAS) has been demonstrated to influence the inflammation and fibrosis in IBD (18). Thus, whether ACE2 or RAS could help for predicting response to anti-TNF $\alpha$ treatment deserves more research. It is unclear whether the concomitant medication influence ACE2 expression. In the present study, of 53 patients with intestinal biopsies pre- and post-anti-TNF therapy, none of them were on concomitant steroid use, and only one patient was on recent methylprednisolone use before anti-TNF therapy. There were 45 patients who received combination therapy of antiTNF with azathioprine (Supplementary Table 2), most of whom had treatment failure of azathioprine before accelerating antiTNF therapy. We further performed a subgroup analysis of patients on anti-TNF and azathioprine therapy and came to the same conclusion that colonic ACE2 was decreased significantly in patients responding to anti-TNF $\alpha$ (endoscopic response, $P$ $=0.0096$; histologic response, $P=0.0039$ ). In recent studies $(14,32)$, international data from SECURE-IBD highlighted the association of corticosteroids with adverse COVID-19 outcomes and the probable safety of anti-TNF. The association between monotherapy or combination therapies and the risk of COVID-19 has been explored in some observational studies $(14,32,42)$. Our study used paired samples before and after anti-TNF therapy, which could minimize the inter-individual differences such as concomitant medication. However, some confounding factors are inevitable in our current retrospective study. Further prospective well-designed studies are needed to validate our results.

Our study also showed that anti-TNF $\alpha$ could downregulate the ACE2 expression level in colon of patients with IBD rather than in ileum. ACE2 in ileum tissue was upregulated significantly in $\mathrm{CD}$ patients using anti-TNF $\alpha$ regardless of the response status (GSE16879, Figure 1A), which demonstrated that anti$\mathrm{TNF} \alpha$ may not influence the ileal ACE2 expression. Numerous previous evidence (43) supported that colonic CD is a different phenotype from ileal $\mathrm{CD}$ at the level of genetics, macroscopic, cellular immunology, microbiota, and treatment. It is worth mentioning that isolated ileal disease location has been observed to be a negative predictor of responses to anti-TNF $\alpha$ therapy in several cohort studies and there was no significant difference in efficacy of VDZ treatment in different locations (44). Therefore, we speculated that the RAS may be an important factor in the TNF-pathway of colonic CD and UC.

There was a positive correlation between epithelial ACE2 expression and disease activity, and the association was stronger using histological score compared to endoscopic score. Endoscopic and clinical measurements are predominately used to determine response to therapy in IBD. There has been growing interest in using histological score as measuring disease activity and treatment outcome. Previous studies (45) have shown that endoscopic assessment and clinical measures may not adequately reflect disease activity, whereas histologic measurement is more sensitive to detect disease activity and predict response to therapy.

One strength of the present study was that we included the data of matched intestinal mucosal biopsies from IBD patients before and after biologic therapy, so participant variables (i.e., individual differences) are reduced. Besides, we provided three sets of data to support our ACE2 expression changes after biologics use especially the down-regulation after anti-TNF $\alpha$ treatment and validated in IBD cohorts from different countries. More importantly, we not only assessed the disease activity and response by endoscopic score but also histological score which was better to illustrate the association between intestinal epithelial ACE2 expression and inflammatory activity.

Several certain limitations also existed. Firstly, because of the inconvenience of collecting biopsies from patients during the COVID19 pandemic, the validation of ACE2 mRNA and protein was conducted in two separate cohorts and a small amount of ileum tissue was included, which limited the assessment of the difference in ACE2 expression between terminal ileum and colon. Besides, we did not include samples for validation of ACE2 protein expression before and after VDZ/UST treatment, given these two biologics were not available in China before 2020. Finally, the validation of ACE2 protein expression did not included UC patients, because there were insufficient numbers of specimens of UC patients with anti-TNF $\alpha$ treatment to conduct statistical analysis. Further research is needed to confirm these findings.

In conclusion, our study showed that colonic ACE2 expression was downregulated after anti-TNF $\alpha$ therapy in IBD patients responding to treatment. This might provide new clues regarding the risk of SARS-CoV-2 infection and the potential benefit of maintaining anti-TNF $\alpha$ treatment in patients with IBD.

\section{DATA AVAILABILITY STATEMENT}

The original contributions generated for this study are included in the article/Supplementary Materials, further inquiries can be directed to the corresponding author/s.

\section{ETHICS STATEMENT}

The studies involving human participants were reviewed and approved by Human Ethics Committee of the First Affiliated Hospital, Sun Yat-sen University. University of Birmingham 
Human Biomaterials Resource Centre. The patients/participants provided their written informed consent to participate in this study.

\section{AUTHOR CONTRIBUTIONS}

RM and M-HC conceived and supervised the overall study. $\mathrm{X}-\mathrm{ZL}, \mathrm{MI}$, and RM wrote the manuscript. FL, RF, Z-YY, J-SH, J-YT, S-NL, SG, MI, M-HC, and RM critically revised the manuscript. X-ZL, YQ, and LJ performed the experiment and analyzed the data. All authors contributed to the article and approved the submitted version.

\section{REFERENCES}

1. Zhou P, Yang $\mathrm{X}$, Wang $\mathrm{X}, \mathrm{Hu} \mathrm{B}$, Zhang $\mathrm{L}$, Zhang $\mathrm{W}$, et al. A pneumonia outbreak associated with a new coronavirus of probable bat origin. Nature. (2020) 579:270-3. doi: 10.1038/s41586-020-2951-Z

2. Du M, Cai G, Chen F, Christiani DC, Zhang Z, Wang M. Multiomics evaluation of gastrointestinal and other clinical characteristics of COVID19. Gastroenterology. (2020) 158:2298-301. doi: 10.1053/j.gastro.2020. 03.045

3. Zhang H, Kang Z, Gong H, Xu D, Wang J, Li Z, et al. Digestive system is a potential route of COVID-19: an analysis of single-cell coexpression pattern of key proteins in viral entry process. Gut. (2020) 69:10108. doi: 10.1136/gutjnl-2020-320953

4. Xiao F, Tang M, Zheng X, Liu Y, Li X, Shan H. Evidence for gastrointestinal infection of SARS-CoV-2. Gastroenterology. (2020) 158:18313. doi: 10.1053/j.gastro.2020.02.055

5. Liang W, Feng Z, Rao S, Xiao C, Xue X, Lin Z, et al. Diarrhoea may be underestimated: a missing link in 2019 novel coronavirus. Gut. (2020) 69:1141-3. doi: 10.1136/gutjnl-2020-320832

6. Zhou J, Li C, Liu X, Chiu MC, Zhao X, Wang D, et al. Infection of bat and human intestinal organoids by SARS-CoV-2. Nat Med. (2020) 26:107783. doi: 10.1038/s41591-020-0912-6

7. Lamers MM, Beumer J, van der Vaart J, Knoops K, Puschhof J, Breugem TI, et al. SARS-CoV-2 productively infects human gut enterocytes. Science. (2020) 369:50-4. doi: 10.1126/science.abc1669

8. An P, Ji M, Ren H, Su J, Ding NS, Kang J, et al. Prevention of COVID-19 in patients with inflammatory bowel disease in Wuhan, China. Lancet Gastroenterol Hepatol. (2020) 5:525-7. doi: 10.1016/S2468-1253(20) 30121-7

9. Taxonera C, Sagastagoitia I, Alba C, Mañas N, Olivares D, Rey E. 2019 novel coronavirus disease (COVID-19) in patients with inflammatory bowel diseases. Aliment Pharm Ther. (2020) 52:276-83. doi: 10.1111/apt.15804

10. Allocca M, Fiorino G, Zallot C, Furfaro F, Gilardi D, Radice S, et al. Incidence and patterns of COVID-19 among inflammatory bowel disease patients from the Nancy and Milan cohorts. Clin Gastroenterol H. (2020) 18:2134-5. doi: 10.1016/j.cgh.2020.04.071

11. Bezzio C, Saibeni S, Variola A, Allocca M, Massari A, Gerardi V, et al. Outcomes of COVID-19 in 79 patients with IBD in Italy: an IG-IBD study. Gut. (2020) 69:1213-7. doi: 10.1136/gutjnl-2020-321411

12. Brenner EJ, Ungaro RC, Colombel JF, Kappelman MD. SECURE-IBD Database Public Data Update. Available online at: covidibd.org (accessed October 1, 2020).

13. Verstockt B, Verstockt S, Abdu Rahiman S, Ke B, Arnauts K, Cleynen $\mathrm{I}$, et al. Intestinal receptor of SARS-CoV-2 in inflamed IBD tissue seems downregulated by HNF4A in ileum and upregulated by interferon regulating factors in colon. J Crohns Colitis. (2020). doi: 10.1093/ecco-jcc/jjaa185. [Epub ahead of print].

14. Suárez-Fariñas M, Tokuyama M, Wei G, Huang R, Livanos A, Jha D, et al. Intestinal inflammation modulates the expression of ACE2 and TMPRSS2

\section{FUNDING}

This work was supported by grants from the National Natural Science Foundation of China (81970483, 81700482), Guangdong Natural Science Foundation (2017A030310211), and Guangdong Medical Research Foundation (A2017292).

\section{SUPPLEMENTARY MATERIAL}

The Supplementary Material for this article can be found online at: https://www.frontiersin.org/articles/10.3389/fmed. 2020.613475/full\#supplementary-material

and potentially overlaps with the pathogenesis of SARS-CoV-2 related disease. Gastroenterology. (2020). doi: 10.1101/2020.05.21.109124. [Epub ahead of print].

15. Burgueño JF, Reich A, Hazime H, Quintero MA, Fernandez I, Fritsch J, et al. Expression of SARS-CoV-2 entry molecules ACE2 and TMPRSS2 in the gut of patients with IBD. Inflamm Bowel Dis. (2020) 26:797808. doi: 10.1093/ibd/izaa085

16. Schurch NJ, Schofield P, Gierliński M, Cole C, Sherstnev A, Singh V, et al. How many biological replicates are needed in an RNA-seq experiment and which differential expression tool should you use? RNA. (2016) 22:83951. doi: 10.1261/rna.053959.115

17. Peyrin-Biroulet L, Sandborn W, Sands BE, Reinisch W, Bemelman W, Bryant RV, et al. Selecting Therapeutic Targets in Inflammatory Bowel Disease (STRIDE): determining therapeutic goals for treat-to-target. Am J Gastroenterol. (2015) 110:1324-38. doi: 10.1038/ajg.2015.233

18. Garg M, Royce SG, Tikellis C, Shallue C, Batu D, Velkoska E, et al. Imbalance of the renin-angiotensin system may contribute to inflammation and fibrosis in IBD: a novel therapeutic target? Gut. (2020) 69:84151. doi: 10.1136/gutjnl-2019-318512

19. Sipponen T, Savilahti E, Kolho K, Nuutinen H, Turunen U, Färkkilä M. Crohn's disease activity assessed by fecal calprotectin and lactoferrin: correlation with Crohn's disease activity index and endoscopic findings. Inflamm Bowel Dis. (2008) 14:40-6. doi: 10.1002/ibd.20312

20. Danese S, Sandborn WJ, Colombel J, Vermeire S, Glover SC, Rimola J, et al. Endoscopic, radiologic, and histologic healing with vedolizumab in patients with active crohn's disease. Gastroenterology. (2019) 157:100718. doi: 10.1053/j.gastro.2019.06.038

21. Regueiro M, Schraut W, Baidoo L, Kip KE, Sepulveda AR, Pesci M, et al. Infliximab prevents crohn's disease recurrence after ileal resection. Gastroenterology. (2009) 136:441-50. doi: 10.1053/j.gastro.2008.10.051

22. Arijs I, De Hertogh G, Lemaire K, Quintens R, Van Lommel L, Van Steen $\mathrm{K}$, et al. Mucosal gene expression of antimicrobial peptides in inflammatory bowel disease before and after first infliximab treatment. PLoS ONE. (2009) 4:e7984. doi: 10.1371/journal.pone.0007984

23. Toedter G, Li K, Marano C, Ma K, Sague S, Huang CC, et al. Gene expression profiling and response signatures associated with differential responses to infliximab treatment in ulcerative colitis. Am J Gastroenterol. (2011) 106:1272-80. doi: 10.1038/ajg.2011.83

24. Sandborn WJ, Feagan BG, Marano C, Zhang H, Strauss R, Johanns J, et al. Subcutaneous golimumab induces clinical response and remission in patients with moderate-to-severe ulcerative colitis. Gastroenterology. (2014) 146:8595. doi: 10.1053/j.gastro.2013.05.048

25. Arijs I, De Hertogh G, Lemmens B, Van Lommel L, de Bruyn M, Vanhove $\mathrm{W}$, et al. Effect of vedolizumab (anti- $\alpha 4 \beta 7$-integrin) therapy on histological healing and mucosal gene expression in patients with UC. Gut. (2017) 67:4352. doi: 10.1136/gutjnl-2016-312293

26. VanDussen KL, Stojmirović A, Li K, Liu T, Kimes PK, Muegge BD, et al. Abnormal small intestinal epithelial microvilli in patients with crohn's disease. Gastroenterology. (2018) 155:815-28. doi: 10.1053/j.gastro.2018.05.028 
27. Higgins PDR, $\mathrm{Ng} \mathrm{S}$, Danese $\mathrm{S}$, Rao $\mathrm{K}$. The risk of SARS-CoV2 in immunosuppressed IBD patients. Crohns Colitis. (2020) 2:a26. doi: 10.1093/crocol/otaa026

28. Neurath MF. COVID-19 and immunomodulation in IBD. Gut. (2020) 69:1335-42. doi: 10.1136/gutjnl-2020-321269

29. Monteleone G, Ardizzone S. Are patients with inflammatory bowel disease at increased risk for Covid-19 infection? J Crohns Colitis. (2020) 14:13346. doi: 10.1093/ecco-jcc/jjaa061

30. Zhuang MW, Cheng Y, Zhang J, Jiang XM, Wang L, Deng J, et al. Increasing host cellular receptor-angiotensin-converting enzyme 2 expression by coronavirus may facilitate $2019-\mathrm{nCoV}$ (or SARS-CoV-2) infection. J Med Virol. (2020) 92:2693-701. doi: 10.1002/jmv.26139

31. Ziegler CGK, Allon SJ, Nyquist SK, Mbano IM, Miao VN, Tzouanas CN, et al. SARS-CoV-2 receptor ACE2 is an interferon-stimulated gene in human airway epithelial cells and is detected in specific cell subsets across tissues. Cell. (2020) 181:1016-35.e19. doi: 10.1016/j.cell.2020.04.035

32. Cappello M, Busacca A, Guida L. The course of Covid 19 in inflammatory bowel disease: protective role of TNF antagonists response to: corticosteroids, but not TNF antagonists, are associated with adverse COVID-19 outcomes in patients with inflammatory bowel diseases: results from an international registry. Gastroenterology. (2020). doi: 10.1053/j.gastro.2020.06.087. [Epub ahead of print].

33. Brennan FM, Chantry D, Jackson A, Maini R, Feldmann M. Inhibitory effect of TNF alpha antibodies on synovial cell interleukin-1 production in rheumatoid arthritis. Lancet. (1989) 2:244-7. doi: 10.1016/S0140-6736(89)90430-3

34. Billmeier U, Dieterich W, Neurath MF, Atreya R. Molecular mechanism of action of anti-tumor necrosis factor antibodies ininflammatory bowel diseases. World J Gastroentero. (2016) 22:9300-13. doi: 10.3748/wjg.v22.i42.9300

35. Feldmann M, Maini RN, Woody JN, Holgate ST, Winter G, Rowland M, et al. Trials of anti-tumour necrosis factor therapy for COVID-19 are urgently needed. The Lancet. (2020) 395:1407-9. doi: 10.1016/S0140-6736(20)30858-8

36. He HL, Liu L, Chen QH, Cai SX, Han JB, Hu SL, et al. MSCs modified with ACE2 restore endothelial function following LPS challenge by inhibiting the activation of RAS. J Cell Physiol. (2015) 230:691-701. doi: 10.1002/jcp.24794

37. Pawlik MW, Kwiecien S, Ptak-Belowska A, Pajdo R, Olszanecki R, Suski $\mathrm{M}$, et al. The renin-angiotensin system and its vasoactive metabolite angiotensin-(1-7) in the mechanism of the healing of preexisting gastric ulcers. The involvement of Mas receptors, nitric oxide, prostaglandins and proinflammatory cytokines. J Physiol Pharmacol. (2016) 67:75-91.
38. Yu W, Ou X, Liu X, Zhang S, Gao X, Cheng H, et al. ACE2 contributes to the maintenance of mouse epithelial barrier function. Biochem Biophys Res Commun. (2020) 533:1276-82. doi: 10.1016/j.bbrc.2020.10.002

39. Hashimoto T, Perlot T, Rehman A, Trichereau J, Ishiguro H, Paolino M, et al. ACE2 links amino acid malnutrition to microbial ecology and intestinal inflammation. Nature. (2012) 487:477-81. doi: 10.1038/nature11228

40. Byrnes JJ, Gross S, Ellard C, Connolly K, Donahue S, Picarella D. Effects of the ACE2 inhibitor GL1001 on acute dextran sodium sulfate-induced colitis in mice. Inflamm Res. (2009) 58:819-27. doi: 10.1007/s00011-009-0053-3

41. Qiu Y, Chen B, Mao R, Zhang S, He Y, Zeng Z, et al. Systematic review with meta-analysis: loss of response and requirement of anti-TNF $\alpha$ dose intensification in Crohn's disease. J Gastroenterol. (2017) 52:53554. doi: 10.1007/s00535-017-1324-3

42. Ungaro RC, Brenner EJ, Gearry RB, Kaplan GG, Kissous-Hunt M, Lewis JD, et al. Effect of IBD medications on COVID-19 outcomes: results from an international registry. Gut. (2020). doi: 10.1136/gutjnl-2020-322539. [Epub ahead of print].

43. Dulai PS, Singh S, Vande Casteele N, Boland BS, Rivera-Nieves J, Ernst PB, et al. Should we divide crohn's disease into ileum-dominant and isolated colonic diseases? Clin Gastroenterol H. (2019) 17:263443. doi: 10.1016/j.cgh.2019.04.040

44. Subramanian S, Ekbom A, Rhodes JM. Recent advances in clinical practice: a systematic review of isolated colonic Crohn's disease: the third IBD? Gut. (2017) 66:362-81. doi: 10.1136/gutjnl-2016-3 12673

45. Pai RK, Geboes K. Disease activity and mucosal healing in inflammatory bowel disease: a new role for histopathology? Virchows Arch. (2018) 472:99110. doi: 10.1007/s00428-017-2156-5

Conflict of Interest: The authors declare that the research was conducted in the absence of any commercial or financial relationships that could be construed as a potential conflict of interest.

Copyright (C) 2021 Li, Qiu, Jeffery, Liu, Feng, He, Tan, Ye, Lin, Ghosh, Iacucci, Chen and Mao. This is an open-access article distributed under the terms of the Creative Commons Attribution License (CC BY). The use, distribution or reproduction in other forums is permitted, provided the original author(s) and the copyright owner(s) are credited and that the original publication in this journal is cited, in accordance with accepted academic practice. No use, distribution or reproduction is permitted which does not comply with these terms. 